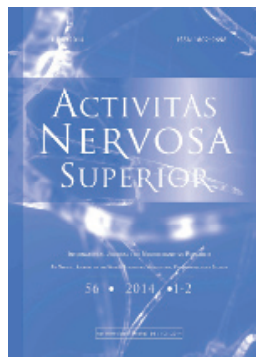

\title{
ARE EDUCATED BETTER IN COGNITION THAN THEIR ANCESTORS? AN INDIAN FLYNN EFFECT STUDY
}

\author{
Ashima Nehra, ${ }^{*}$ Vishnubhatla Sreenivas, Harsimarpreet Kaur, Sakshi Chopra, \\ Swati Bajpai
}

All India Institute of Medical Sciences, New Delhi, India

\begin{abstract}
Flynn Effect (FE) deals with the issue of how the general scores of a population change over time. The existing cognitive test was developed in 1976 and since then there have been a lot of modernization and technological changes in the country. Hence, the objective was to study the possible FE with respect to cognition in the country. A sample of 142 people was assessed in 1976 to make norms on Post Graduate Institute- Memory Scale (PGI-MS). To compare these results the present study included 140 consenting subjects in 2013 almost in the forth decade after the first study. PGIMS is an original and one of the most popular tests of cognition in India, developed by Dwarka Pershad \& N.N.Wig. It measures the cognitive ability, even with the illiterate population. Comparison of the age related norms (1976 and 2013) after 37 years shows that there was FE seen in the age group 20-29 years in the domains of attention and concentration $(p=0.04)$, delayed recall $(p=0.001)$ and recognition ( $p=0.05)$. 30-39 years age group also shows the evidence of FE in retention for dissimilar pairs i.e. ability for new learning ability ( $p=0.001$ ). Finally, in the age group of $40-49$ years there was FE seen in immediate recall $(\mathrm{p}=0.0007)$ and retention for similar pairs i.e. ability for simple memory $(p=0.01)$. Whereas there was no FE seen in ages between 50-69 years i.e. amongst the senior citizens. Results show there is a shift in the cognition to a higher continuum. The conclusions made on the cognitive abilities for persons between 20 to 49 years, on the bases of age old norms, is an underestimate of their present abilities. On the basis of this study it can be inferred that, there is a change in cognitive abilities over generations, as Flynn (2012) stated, human beings are not getting smarter they are just being more modern. Hence, there is a need to revise the available norms of the test, across all the ages and education level, for assessing the cognitive functioning to make them more valid and reliable for clinical and research purposes.
\end{abstract}

Key words: Neuropsychology; Memory; Cognition; Flynn effect; PGI-MS

\section{INTRODUCTION}

In clinical neuropsychology and cognitive sciences, "cognition" usually refers to an information processing view of an individual's psychological functions. It is also used in a branch of social psychology called social cognition to explain attitudes, attribution, and group's dynamics (Sternberg \& Sternberg, 2009). In cognitive psychology and cognitive engineering, cognition is typically assumed to be information processing in a participant's or operator's mind or brain (Blomberg, 2011). Memory, in neuropsychology is the process

${ }^{*}$ Correspondence to: Ashima Nehra, email: ashimanwadhawan@gmail.com

Received December 8, 2013; accepted July 15, 2014; Act Nerv Super 56(1-2), 45-51; ISSN-1802-9698 
by which information is encoded, stored, and retrieved. Encoding, the first stage, allows information that is from the outside world to reach our senses in the forms of chemical and physical stimuli. Storage is the second memory stage which entails that we maintain information over periods of time. Finally the third process is the retrieval of information that we have stored. We must locate it and return it to our consciousness. Some retrieval attempts may be effortless due to the type of information (Greenberg, Rice, \& Elliott, 1996).

Flynn Effect is the substantial and long-sustained increase in test scores measured in many parts of the world from roughly 1930 to the present day. When intelligence quotient (IQ) tests are initially standardized using a sample of test-takers, by convention the average of the test results is set to 100 and their standard deviation is set to 15 or 16 IQ points. When IQ tests are revised, they are again standardized using a new sample of test-takers, usually born more recently than the first (Flynn, 1987). Again, the average result is set to 100 . However, when the new test subjects take the older tests, in almost every case their average scores are significantly above 100 . There are numerous proposed explanations of the Flynn effect, as well as some skepticism about its implications. Similar improvements have been reported for other cognitions such as semantic and episodic memory (Rönnlund, \& Nilsson, 2009).

Extensive review on the Flynn Effect shows that it was studied in relationship to Intelligence Functioning. A study on Verbal memory abilities has been done by (Baxendale, 2010). There were no studies of Flynn Effect on Cognition. However, there were no studies from India on Flynn Effect (neither on Intellectual Functioning, nor on Cognition). Since, assessment of information processing is an important domain of neuropsychological evaluation, hence, it was important to know if there was a need for periodical revision of popular cognitive tests of India.

Since, PGIMS (Pershad \& Wig, 1976) is one of a popular test to assess cognition in a short span. It is an originally devised test, which can be administered even on illiterate population. The existing norms of the test were developed in 1976 (34 years ago) and since then there have been a lot socio-cultural changes, educational difference, economic technological changes and modernization of society that has taken place in the country. The Flynn Effect which is a substantial and long sustained increase in test scores measured in many parts of the world from roughly 1930 to the present day (Ronnlund \& Nilsson 2009). Therefore, the study was planned to understand the effect of possible Flynn Effect so that updated and revised scales could be made available for assessing memory impairments. In this context objective of the study was to examine the evidence of Flynn Effect in the existing norms for 20 to 69 years age and in education category of more than 10 years of schooling.

\section{METHODS}

A sample of 142 people was assessed in 1976 to make norms on PGI-MS. The present study included 140 consenting subjects in 2013 almost in the forth decade after the first study (to match the original study). The number of males and females were not mentioned in the original study. But an attempt was made to include equal number of consenting males and females. There were total of 84 males and 56 females, who were administered PGI-MS with the age range of 20 years to 69 years with education level of 10th standard and above to match the original study.

Inclusion criteria- All consenting individuals, age: 20 to 69 years; Education level: more than 10 years of schooling; Both genders (efforts were made for equal numbers of each); Both Right/left handedness.

Exclusion Criteria- Below the age of 20 years; Above the age of 69 years; Any history of psychiatric illness; Any major neurological disorder; Mental retardation; Acute brain trauma; Any systematic illness; Brain trauma; Head injury; Non-consenting individuals. 
Tools- Post Graduate Institute- Memory Scale (PGI-MS) by Dwarka Pershad \& N.N.Wig, 1976 which is a battery to assess the cognitive functions i.e.: 1 . Remote memory including ability to remember personal/ historical events of the past; 2. Recent Memory including ability To remember relatively new information; 3 . Mental Balance related to temporal sequencing; 4. Digit span (forward and backward) related to attention and concentration, mental control, working memory; 5 . Immediate recall related to short- term memory; 6. Delayed Recall related to verbal working memory; 7 . Retention for similar pairs related to simple learning ability; 8. Retention for dissimilar pairs related to new learning ability; 9. visual retention related to visuo-spatial memory; 10. Recognition related to visual and verbal memory (Pershad \& Wig, 1976).

Data collection- The sample for the present study includes a normative data collected from consenting persons. The subjects for the same were chosen from volunteers working/studying in colleges (public and government, of Delhi), N.G.O.'s (Non Government Organization), resident welfare associations, old age homes, senior citizen associations in the catchment area of NCR (National Capital Region). The age of the subjects will be 20 to 69 years of age. Consent forms from the subjects were signed before hand. Finally, they were assessed on a series of cognitive functioning tests, using PGI Memory Scale.

\section{RESULTS}

All results of the study including comparisons of the age-related norms on Post Graduate Institute- Memory Scale (PGI-MS) used to see the role of Flynn effect in cognition amongst educated Indian population between 20 to 69 years of age are included in Table 1 . The different domains of cognitive functioning in PGI-MS were recent memory, remote memory, mental balance, attention and concentration, delayed recall, immediate recall, retention for similar pairs, retention for dissimilar pairs, visual retention and recognition. The total of all the domains were also taken for the different age groups, namely, 20-29 years, 30-39 years, $40-49$ years, $50-59$ years and 60-69 years with more than 10 years of education.

From comparison of the age related norms of 1976 and 2013 (after 37 years), as seen in Table 1, a Flynn effect was found in the age group 20-29 years in the domains of attention and concentration $(p=0.04)$, delayed recall $(p=0.001)$ and recognition $(p=0.05)$. 30-39 years age also shows the evidence of Flynn effect in retention for dissimilar pairs i.e. ability for new learning ability $(p=0.001)$. Finally, in the age group of $40-49$ years there was Flynn effect seen in immediate recall $(\mathrm{p}=0.0007)$ and retention for similar pairs i.e. ability for simple memory ( $p=0.01$ ). Whereas there was no Flynn effect seen in ages between 50-69 years.

\section{DISCUSSION}

The primary objective for the present research was to study the Flynn Effect in Cognition amongst educated Indian Population. To assess all educated age groups between 20 to 69 years having education more than Standard 10th for use in research and clinical comparisons of performance levels longitudinally. The hypothesis which was ascertained before the study was planned, that, there will be no changes seen in the existing PGI-MS norms for the age and education groups. The Flynn effect refers to the steady increase in cognitive test scores that appears to date back at least to the inception of modern-day cognitive tests. When tests are revised, they are again standardized using a new sample of test-takers, usually born more recently than the first. However, when the new test subjects take the older tests, in almost every case their average scores are significantly above 100 (Flynn, 1987). In our present research a periodical revision was thought necessary to find an age and time appropriate average range of cognitive functioning. 


\begin{tabular}{|c|c|c|c|c|c|}
\hline 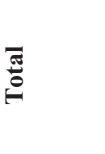 & 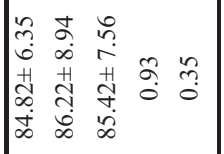 & 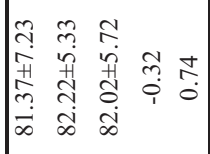 & 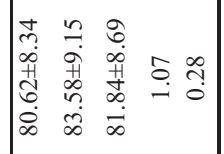 & 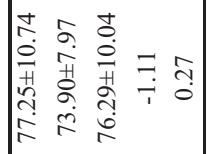 & 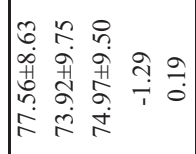 \\
\hline : & 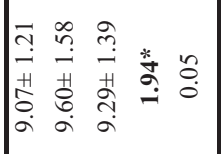 & 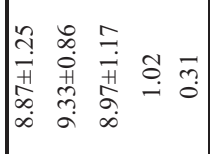 & 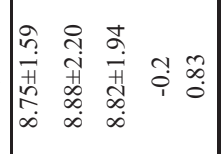 & 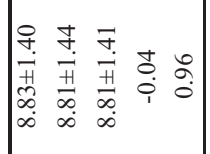 & 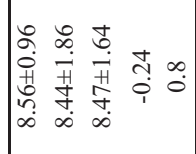 \\
\hline 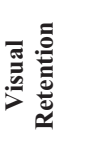 & 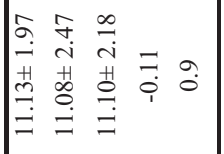 & 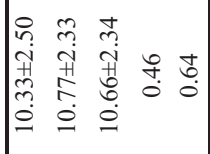 & 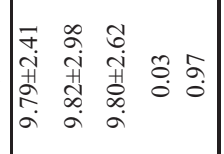 & 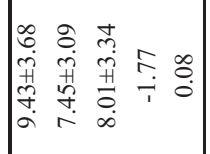 & 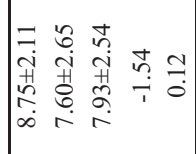 \\
\hline 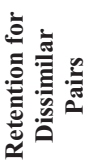 & 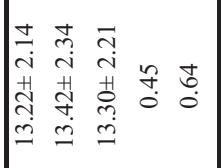 & 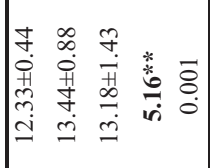 & 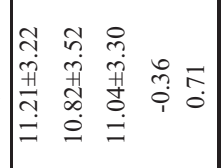 & 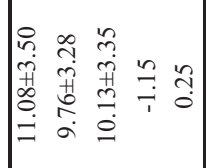 & 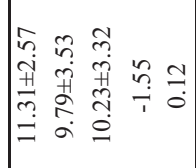 \\
\hline 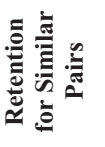 & 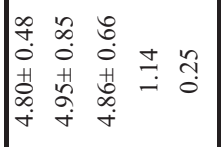 & 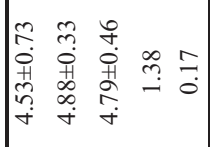 & 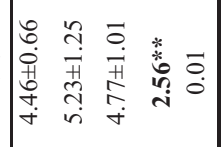 & 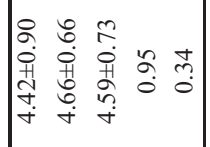 & 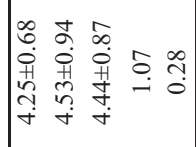 \\
\hline 芯 & 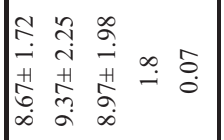 & 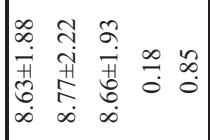 & 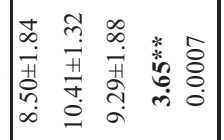 & 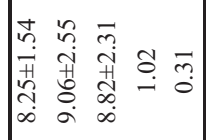 & 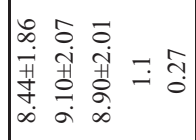 \\
\hline 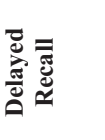 & 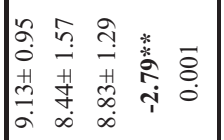 & 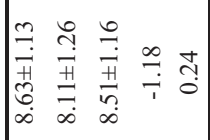 & 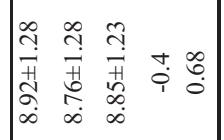 & 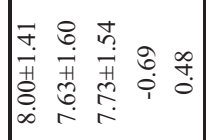 & 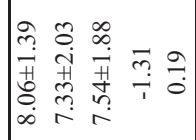 \\
\hline Uू. & 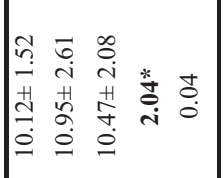 & 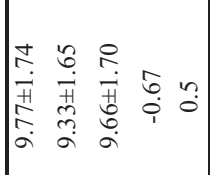 & 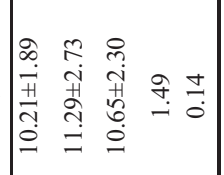 & 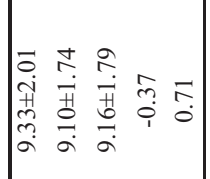 & 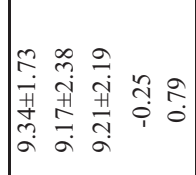 \\
\hline 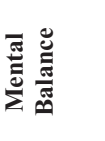 & 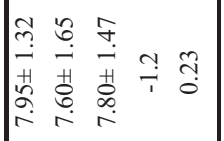 & 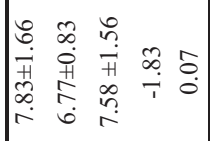 & 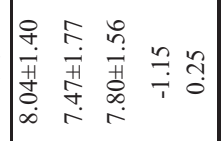 & 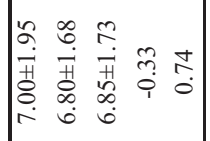 & 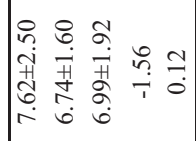 \\
\hline 产 & 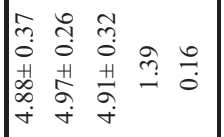 & $\begin{array}{lllll}m & \vec{m} & \vec{n} & & \\
m & \tilde{0} & 0 & 0 \\
0 & 0 & 0 & 0 & 0 \\
+1 & 0 & 0 & 0 & 0 \\
0 & \infty & \infty & 0 & 0 \\
\dot{+} & \infty & \dot{+} & 1 & \end{array}$ & 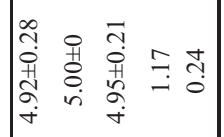 & 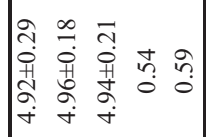 & 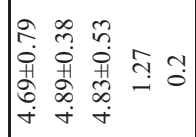 \\
\hline 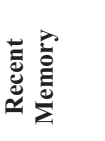 & 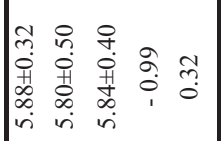 & 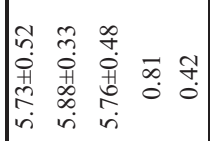 & 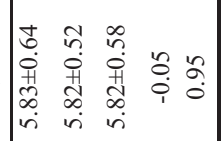 & 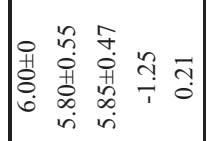 & 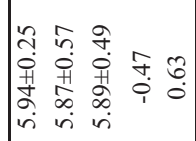 \\
\hline$\Xi$ & 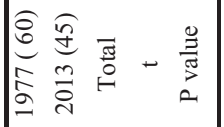 & 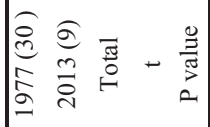 & 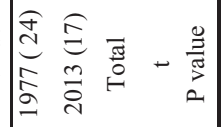 & 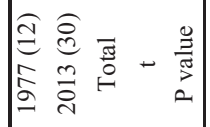 & 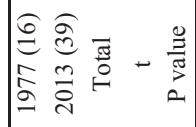 \\
\hline ن & 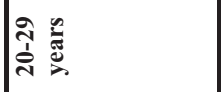 & 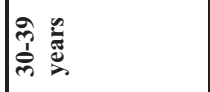 & 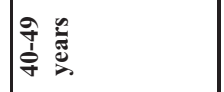 & $\begin{array}{l}\text { în } \\
\text { in } \\
\text { in }\end{array}$ & 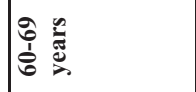 \\
\hline
\end{tabular}


This was thought necessary because the life style of an average Indian has changed over the time. Current population of India with 1,270,272,105 (1.27 billion) people is the second most populous country in the world. India is going through a technological revolution. Technology has become an integral part of every citizen of the country. The most important technology to change our lives is the mobile phone. Mobile phones are used by all different sections of the society. At present, India has 15 million mobile users on an average (Kumar \& Thomas, 2006). "TIME Magazine reports that in 2000, the number of cell phone subscribers was 2 millions and that number has climbed to 545 million in early 2010." The literacy rate of India has grown from 52.2\% in 1991 to 74.04 \% in 2011 ("Education in India", 2011). The right to education at elementary level has been made one of the fundamental rights of the country which ensures free education to all children (Astill, 2008). Therefore, it becomes important to study the Flynn effect on cognitive functioning in India.

In the present study, comparisons of the age-related norms on Post Graduate InstituteMemory Scale (PGI-MS) was used to see the role Flynn effect in cognition amongst educated Indian population between 20 to 69 years of age. The different domains of cognitive functioning in PGI-MS were recent memory, remote memory, mental balance, attention and concentration, immediate recall, retention for similar pairs, retention for dissimilar pairs, visual retention and recognition. The total of all the domains was also taken for the different age groups, namely, 20-29 years, 30-39 years, 40-49 years, 50-59 years and 60-69 years all more than 10 years of education.

On comparing the means and standard deviation of 1976 group and 2013 group (See Table 1), the results show that there is Flynn effect evident in the ages between 20 till 49 years. In the age group of 20-29 years there is a significant difference in the norms of 1976 and 2013 for attention and concentration, delayed recall and recognition i.e. the people who were assessed 2013 are better in attention and concentration, delayed recall and recognition than the people who were assessed 1976.

In the age category of 30-39 years, there were statistically significant differences between norms of 1976 and 2013 in retention for dissimilar pair's i.e. the people who were assessed in 2013 are better in the new learning ability than the people who were assessed in 1976.

There is Flynn effect evident in immediate recall and retention for similar pairs for the age group 40-49 years. There is statistically significant difference among the norms of 1976 and 2013 in the immediate recall and simple learning ability i.e. the people of 2013 have a better ability on immediate recall and simple learning ability than people who were assessed in 1976.

Recent research which supports these results states that there is a significant Flynn effect on tests of memory functions. This effect appears to be material specific with statistically significant improvements in all scores on tests involving the learning and recall of visual material in every age range evident over a 22-year period ranges (Baxendale, 2010). Another study concluded that changing proportions of sibship sizes had a moderate effect both on General Ability and the subtest scores, and that most of the changes were connected to changing sibship means across cohorts (Sundet, Borren \& Tambs, 2008).

On comparing the means and standard deviation of 1976 and 2013 (Table 1), the results reveal that there is no Flynn effect seen i.e. there is statistically no significance in the further discussed categories. In the age category of 20 to 29 years, the means and standard deviation of recent memory, remote memory, mental balance, immediate recall, retention for similar pairs, retention for dissimilar pairs, visual retention and the total of all the 10 cognitive domains in PGI-MS no Flynn effect was seen i.e. there is no change among the norms of 1976and 2013 for the above mentioned categories.

In 30 to 39 years of age category, there was no Flynn effect seen in recent memory, remote memory, mental balance, attention and concentration, delayed recall, immediate recall, retention for similar pairs, visual retention and recognition as well as on the total of all the cognitive functioning i.e. the people who were assessed in 2013 showed no significant difference than people who were assessed in 1976 on the above mentioned domains.

There was no statistically significant difference among the people assessed in 2013 and 1976 which shows an evidence that there was no Flynn effect evident in the following domains of cognitive functioning in the 40 to 49 years age category namely, recent memory, 
remote memory, mental balance, attention and concentration, delayed recall, retention for dissimilar pairs, visual retention, and recognition and also on the total of all the cognitive functions. In the age group of 50 to 59 years and 60 to 69 years there was no Flynn effect seen in all the ten domains of cognitive functioning as well as on the total of all these domains i.e. they appear to be relatively stable with no significant differences between the scores of 1976 and 2013.

Recent research suggests that the Flynn Effect may have ended in at least a few developed nations possibly allowing national differences in IQ scores (Lynn \& Vanhanen, 2006). To diminish if the Flynn Effect continues in nations with lower average national IQs (Teasdal \& Owen, 2008). Verbal memory abilities appear to be relatively stable with no significant differences between the scores in the majority of age ranges (Baxendale, 2010).

The ultimate cause behind such results is the Industrial Revolution. It affects our society in innumerable ways. The intermediate causes are things like smaller family size. If you have a better ratio of adults to children in the home, than an adult vocabulary predominates rather than a child vocabulary. Family size fell in the last century throughout the country (Orenstein, 1961). Formal schooling is extremely important. In 1910, schools were focused on kids memorizing things about the real world. Today, they are entirely about relationships. There is also the fact that so many more of us are pursuing cognitively demanding professions. Compared to even 1950, the number of people who are doing technical, managerial or professional jobs has risen enormously (Goldar, 2000). The fact that our leisure has switched away from merely recovery from work towards cognitively taxing pleasures, like playing video games, has also been important.

In a study that allowed us to understand the type of usage and perception of Information and Communication Technologies (ICT) by the elderly of Lisbon. While most of the respondents had and used a mobile phone, the majority did not use computers or the Internet. The lack of functional literacy in ICT was the main reason to not use a computer or the Internet. Education was significantly related to mobile phone, computer, and Internet usage. Education levels might be, therefore, an important factor to explain the low adoption of these technologies by the elderly. The lack of necessity was also a reason, even if relatively less reported than the functional literacy. Interesting enough, age was also pointed as a reason for not using a computer. The majority of the elderly of their study didn't think they were too old for technology and didn't perceive or present themselves as technophobic. However, they faced a significant amount of difficulties: lack of digital literacy, lack of access to a computer, problems of accessibility and usability, and lack of confidence due to age. Finally, the idea of faux users which states that the users didn't use a computer and the Internet, yet their family would setup it up for them, and so they could talk to family members and friends through the Internet. They wouldn't, however, touch the keyboard or feel that they could use it on their own, while feeling that they were having an engaging social experience (Neves, 2012). Flynn concludes that human beings are not getting smarter they are just being more modern (Flynn, 2012). Hence, there is a need to revise the available norms of the tests assessing the cognitive functioning to make them more valid for clinical and research purposes.

The limitations of the present study are a relatively small sample size in all the age groups amongst the educated i.e. more than 10 years of schooling. Thus, generalizations cannot be made. Even though our sample size is almost the same as the original sample i.e. $\mathrm{n}=142$ (1976) Vs n=140 (2013). To overcome this limitation the future directions are to collect normative sample for all the age groups, namely, 20-29 years, 30-30 years, 40-49 years, 50-59 years, 60-69 years including all education levels, namely, 0-5 years of education, 6-9 years and more than 10 years, till we achieve a sufficient sample in each category with approximately equal number of males and females to study Flynn effect along with gender differences in cognitive functioning. Hence, there is a need to do periodical revision of the available norms of the tests assessing the cognitive and intellectual functioning to make them more valid for clinical and research purposes at present. 


\section{REFERENCES}

Astill, J. (2008). An elephant, not a tiger: A special report on India. Economist Newspaper, December 13.

Baxendale, S. (2010). The Flynn effect and memory function. Journal of Clinical and Experimental Neuropsychology, 32, 699-703.

Blomberg, O. (2011). Conceptions of Cognition for Cognitive Engineering. The International Journal of Aviation Psychology, 2, 85-104.

Flynn, J. R. (1987). Massive IQ gains in 14 nations: What IQ tests really measure. Psychological Bulletin, $101,171$.

Flynn, J. R. (2012). Are We Getting Smarter?: Rising IQ in the Twenty-first Century. Cambridge University Press.

Goldar, B. (2000). Employment growth in organised manufacturing in India. Economic and Political Weekly, 1191-1195.

Greenberg, L. S., Rice, L. N., \& Elliott, R. (1996). Facilitating emotional change: The moment-by-moment process. The Guilford Press.

Kumar, K. J., \& Thomas, A. O. (2006). Telecommunications and Development The Cellular Mobile 'Revolution'in India and China. Journal of Creative Communications, 1, 297-309.

Lynn, R., \& Vanhanen, T. (2006). IQ and Global Inequality. Washington: Washington Summit Publishers.

Neves, B. B. (2012). Too old for technology? How the elderly of Lisbon use and perceive ICT. The Journal of Community Informatics, 8(1).

Orenstein, H. (1961). The recent history of the extended family in India. Social Problems, 8, 341-350.

Pershad, D., \& Wig, N. N. (1976). A battery of simple tests of memory for use in India. Neurology India 24, 86-93

Rönnlund, M., \& Nilsson, L. G. (2009). Flynn effects on sub-factors of episodic and semantic memory: Parallel gains over time and the same set of determining factors. Neuropsychologia, 47, 2174-2180.

Sternberg, R. J., \& Sternberg, K. (2009). Cognitive Psychology (6th Ed.). Belmont, CA: Wadsworth, Cengage Learning.

Sundet, J. M., Borren, I., \& Tambs, K. (2008). The Flynn effect is partly caused by changing fertility patterns. Intelligence, 36, 183-191.

Teasdale, T. W., \& Owen, D. R. (2008). Secular declines in cognitive test scores: A reversal of the Flynn Effect. Intelligence, 36, 121-126.

World Bank (2011). "Education in India". Retrieved 2011-01-13. 